\title{
Common conditions associated with displacement of the inferior alveolar nerve canal: A radiographic diagnostic aid
}

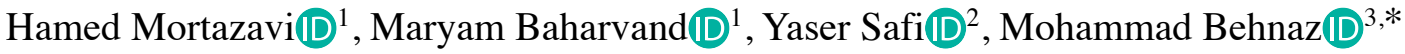 \\ ${ }^{1}$ Department of Oral Medicine, School of Dentistry, Shahid Beheshti University of Medical Sciences, Tehran, Iran \\ ${ }^{2}$ Department of Oral and Maxillofacial Radiology, School of Dentistry, Shahid Beheshti University of Medical Sciences, Tehran, Iran \\ ${ }^{3}$ Department of Orthodontics, School of Dentistry, Shahid Beheshti University of Medical Sciences, Tehran, Iran
}

\section{ABSTRACT}

Purpose: This study reviewed the common conditions associated with displacement of inferior alveolar nerve canal. Materials and Methods: General search engines and specialized databases including Google Scholar, Pub Med, Pub Med Central, Science Direct, and Scopus were used to find relevant studies by using keywords such as "mandibular canal", "alveolar canal", "inferior alveolar nerve canal", "inferior dental canal", "inferior mandibular canal" and "displacement".

Results: About 120 articles were found, of which approximately 70 were broadly relevant to the topic. We ultimately included 37 articles that were closely related to the topic of interest. When the data were compiled, the following 8 lesions were found to have a relationship with displacement of mandibular canal: radicular/residual cysts, dentigerous cyst, odontogenic keratocyst, aneurysmal bone cyst, ameloblastoma, central giant cell granuloma, fibrous dysplasis, and cementossifying fibroma.

Conclusion: When clinicians encounter a lesion associated with displaced mandibular canal, they should first consider these entities in the differential diagnosis. This review would help dentists make more accurate diagnoses and develop better treatment plans according to patients' radiographs.(Imaging Sci Dent 2019; 49: 79-86)

KEY WORDS: Mandibular Nerves; Odontogenic Cysts; Odontogenic Tumors

\section{Introduction}

The inferior alveolar nerve canal (IANC) contains the inferior alveolar nerve and blood vessels. It supplies blood to the mandibular structures and innervates the mandible, lips, teeth, and adjacent structures. Considering the important sensory function of the inferior alveolar nerve, surgeons must pay utmost attention not to damage the IANC during surgical procedures in this area to prevent related postoperative complications. ${ }^{1,2}$ The IANC may have several anatomical variations, and it may be affected by several types of jaw lesions, causing its displacement. ${ }^{1}$ Periapical radi-

Received July 30, 2018; Revised October 6, 2018; Accepted October 19, 2018 *Correspondence to : Prof. Mohammad Behnaz

Department of Orthodontics, School of Dentistry, Shahid Beheshti University of Medical Sciences, Chamran Highway, Tabnak St., Daneshjoo Blvd, 1983963113, Tehran, Iran

Tel)98-21-29902311,E-mail)m.behnaz@sbmu.ac.ir ography, panoramic radiography, computed tomography, and cone-beam computed tomography are efficient imaging modalities for evaluating the position of the IANC. ${ }^{3}$ The IANC initiates from the medial surface of the ramus and extends towards the mental foramen in the body of the mandible. The mandibular canal path has an S-shaped pattern in bone. In the third molar region, the mandibular canal is located most laterally and is nearest to the buccal cortical bone. It then approximates the lingual plate in the first molar region. The mandibular canal changes its path towards the buccal cortical plate between the premolar teeth before exiting the mandible through the mental foramen. In the sagittal plane, the inferior alveolar nerve begins its course in the mandible upward and lingually, at approximately $10 \mathrm{~mm}$ from the sigmoid notch. It reaches its lowest position in the first molar to second premolar region, with a distance of roughly $7.5 \mathrm{~mm}$ from the inferior 
border of the mandible, where it branches into the incisive and mental nerves. The distance between the IANC and the buccal cortical plate in the molar region is greater than that in the ramus region. This distance varies from $0.57 \mathrm{~mm}$ to $5.8 \mathrm{~mm}$ in the ramus region and from $0.40 \mathrm{~mm}$ to $70 \mathrm{~mm}$ in the molar region. These variations in values reported in the literature may be attributed to differences in age and race, as well as anatomical variations. ${ }^{4}$ A comprehensive literature review identified 8 types of jaw lesions that may cause displacement of the IANC, including odontogenic cysts, pseudocyst, tumors, and hamartomatous lesions associated with displacement of the IANC. These entities should be included in the differential diagnosis when encountering a lesion in close proximity of the IANC, causing its displacement. This overview seeks to assist clinicians in making an accurate and timely differential diagnosis by focusing on the relevant radiographic findings. Displacement of the IANC might be asymptomatic, but when associated with some jaw lesions, it can be regarded as an important radiographic finding relevant for the diagnosis.

\section{Materials and Methods}

For this narrative review article, an electronic search of the literature was carried out by the first author and the corresponding author in the Google Scholar, PubMed, PubMed Central, Science Direct, and Scopus databases for relevant articles using the following keywords: "mandibu- lar canal," "alveolar canal," "inferior alveolar nerve canal," "inferior dental canal," "inferior mandibular canal," "displacement," and "deviation." A total of 120 articles were found, of which 70 were relevant to our topic of interest. Thirty-three articles were excluded from the review process since they were duplicates, were written in languages other than English, or their full texts were not available. Finally, 37 English-language articles published from 1977 to 2017 in dental journals that were closely related to our topic of interest were analyzed. These articles consisted of 24 original papers, 4 reviews, and 9 case reports and case series.

\section{Results}

After data collection, the following 8 types of lesions were found to have a correlation with displacement of the IANC: radicular/residual cyst, dentigerous cyst, odontogenic keratocyst, aneurysmal bone cyst, ameloblastoma, central giant cell granuloma, fibrous dysplasia, and cemento-ossifying fibroma. The characteristics of these lesions are summarized in Table 1.

\section{Radicular/residual cyst}

Radicular/residual cysts are associated with teeth with pulpitis or faulty root canal treatment. Periapical lesions are seen in $34 \%$ of teeth with deep carious lesions, and there is a relationship between carious lesions and periapical changes. ${ }^{5}$ Radicular/residual cysts are the most common cysts

Table 1. General characteristics of jaw lesions associated with displacement of the inferior alveolar nerve canal

\begin{tabular}{|c|c|c|c|c|c|c|}
\hline Entity & $\begin{array}{c}\text { Age } \\
\text { (decade } \\
\text { of life) }\end{array}$ & Sex & $\begin{array}{l}\text { Predominant } \\
\text { jaw }\end{array}$ & Radiographic features & $\begin{array}{c}\text { Canal } \\
\text { displacement } \\
\text { rate }\end{array}$ & $\begin{array}{c}\text { Type of } \\
\text { displacement }\end{array}$ \\
\hline $\begin{array}{l}\text { Radicular/residual } \\
\text { cyst }^{6-8}\end{array}$ & $3 \mathrm{rd}, 4$ th & $\mathrm{M}>\mathrm{F}$ & - & Oval radiolucency with cortical margin & - & Inferior \\
\hline Dentigerous cyst ${ }^{9-11}$ & 2nd, 3rd & $M>F$ & $\operatorname{Man}>\operatorname{Max}$ & Pericoronal radiolucency & $42 \%$ & Inferior \\
\hline $\begin{array}{l}\text { Odontogenic } \\
\text { keratocyst }^{10,12}\end{array}$ & 2 nd-5th & $\mathrm{M}>\mathrm{F}$ & $\operatorname{Man}>\operatorname{Max}$ & $\begin{array}{l}\text { Unilocular or multilocular radiolucency with } \\
\text { smooth or scalloped margin }\end{array}$ & $\begin{array}{l}46.2 \% \\
53.8 \%\end{array}$ & $\begin{array}{l}\text { Inferior; buccal/ } \\
\text { lingual }\end{array}$ \\
\hline $\begin{array}{l}\text { Aneurysmal bone } \\
\text { cyst }^{13,14}\end{array}$ & $1 \mathrm{st}-3 \mathrm{rd}$ & $\mathrm{F}>\mathrm{M}$ & Man $>$ Max & $\begin{array}{l}\text { Unilocular radiolucency/ballooned-out } \\
\text { multilocular radiolucency }\end{array}$ & - & Inferior; lingual \\
\hline Ameloblastoma $9,10,17$ & 3 rd-5th & $\mathrm{M}>\mathrm{F}$ & Man $>$ Max & Unilocular or multilocular radiolucency & $\begin{array}{l}15.4 \% \\
84.6 \%\end{array}$ & $\begin{array}{l}\text { Inferior; buccal/ } \\
\text { lingual }\end{array}$ \\
\hline $\begin{array}{l}\text { Central giant cell } \\
\text { granuloma }^{20,21}\end{array}$ & $1 \mathrm{st}-3 \mathrm{rd}$ & $\mathrm{F}>\mathrm{M}$ & $\operatorname{Man}>\operatorname{Max}$ & Unilocular or multilocular radiolucency & - & Inferior; lingual \\
\hline Fibrous dysplasia ${ }^{24,25}$ & $\begin{array}{l}\text { 1st-3rd, } \\
\text { 4th-6th }\end{array}$ & $\begin{array}{c}\mathrm{M}=\mathrm{F} \text { or } \\
\mathrm{F}>\mathrm{M}\end{array}$ & Man $>$ Max & $\begin{array}{l}\text { Poorly defined, mixed to radiopaque; } \\
\text { ground-glass; orange-peel }\end{array}$ & $>60 \%$ & Superior \\
\hline $\begin{array}{l}\text { Cemento-ossifying } \\
\text { fibroma }^{24,32}\end{array}$ & 2nd-4th & $\mathrm{F}>\mathrm{M}$ & Man $>$ Max & Radiolucent/mixed or opaque & $\begin{array}{l}50 \% \\
56 \%\end{array}$ & Inferior \\
\hline
\end{tabular}

M: male, F: female, Man: mandible, Max: maxilla 


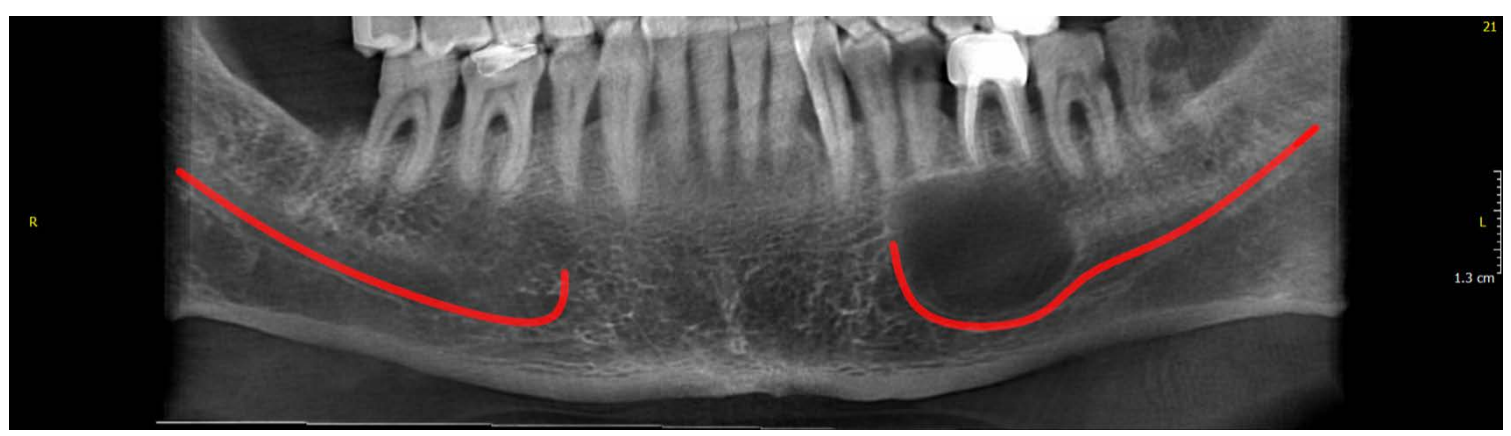

Fig. 1. A panoramic reconstructed cone-beam computed tomographic image shows downward displacement of the mandibular canal in a patient with a radicular cyst.

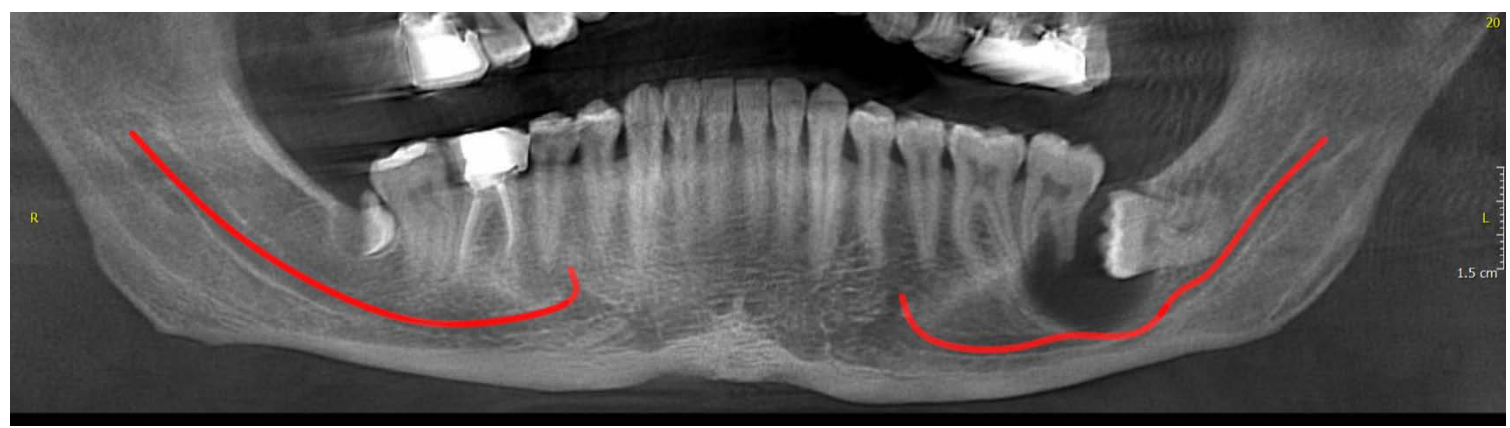

Fig. 2. A panoramic reconstructed cone-beam computed tomographic image shows the inferiorly displaced mandibular canal in a patient with a dentigerous cyst.

found in the jaw, accounting for $52 \%$ to $60 \%$ of all jaw cysts. ${ }^{6}$ Residual cysts may develop in a residual granuloma left after tooth extraction, and account for roughly $10 \%$ of all odontogenic cysts. ${ }^{6,7}$ They are most commonly seen in the third and fourth decades of life and have a male predilection. ${ }^{8}$ Radiographically, they appear as well-defined, round to oval radiolucent lesions with a cortical margin(Fig. 1). These cysts may cause expansion of the cortical plates, invaginate into the maxillary sinus, or depress the IANC. ${ }^{6}$ In a case series, Farman et al. ${ }^{9}$ demonstrated that radicular and residual cysts have similar features. Small cysts occasionally cause resorption of the IANC. Larger cysts do not cause resorption of the mandibular canal; instead, the mandibular canal is often displaced downward by the pressure of the cyst while remaining intact.

\section{Dentigerous cyst}

Dentigerous cysts are developmental cysts that are often associated with the crown of an impacted or unerupted tooth. Dentigerous cysts are the second most common type of odontogenic cysts after radicular cysts, and account for $16 \%$ to $24 \%$ of all true cysts of the jaws. ${ }^{10}$ Most dentig- erous cysts are reported in the second and third decades of life, with a slight predilection for males. ${ }^{10,11}$ Dentigerous cysts most often involve the mandibular third molars (65\%), followed by the maxillary canines and third molars. ${ }^{10}$ Radiographically (Fig. 2), a dentigerous cyst appears as a well-defined, unilocular, radiolucent lesion 3-4 mm in diameter located adjacent to the crown of an impacted tooth. ${ }^{10}$ Dentigerous cysts can cause displacement of the maxillary sinus, IANC, or the nasal fossa. ${ }^{11}$ Zerrin et al. ${ }^{11}$ reported loss of the lamina dura and displacement of the IANC and the maxillary sinus floor in 50\%, 42\%, and 33\% of cases, respectively. Farman et al. ${ }^{9}$ stated that the effects of dentigerous cysts on the IANC depend on the size of the cyst and the position of the involved tooth. Small cysts surrounding the crown of a vertically or laterally positioned tooth have an insignificant effect on the IANC. However, small cysts around inverted teeth may lead to IANC displacement, as do radicular cysts. Large cysts can lead to downward displacement of the IANC and even result in complete loss of mandibular canal margins radiographically, irrespective of the direction of tilting of the affected tooth. 


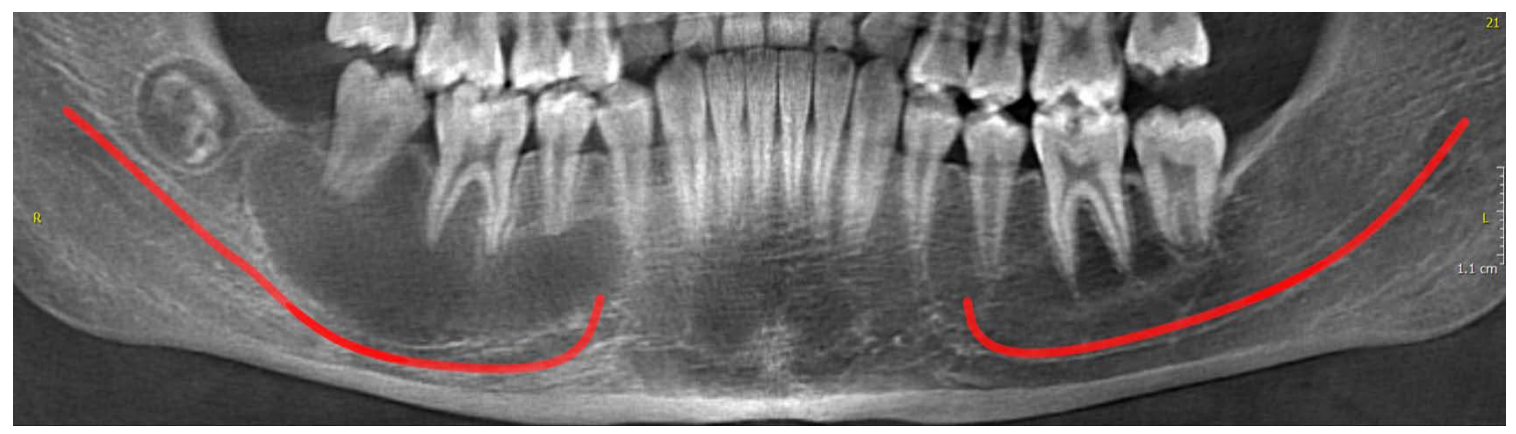

Fig. 3. A panoramic reconstructed cone-beam computed tomographic image shows downward displacement of the mandibular canal in a patient with an odontogenic keratocyst.

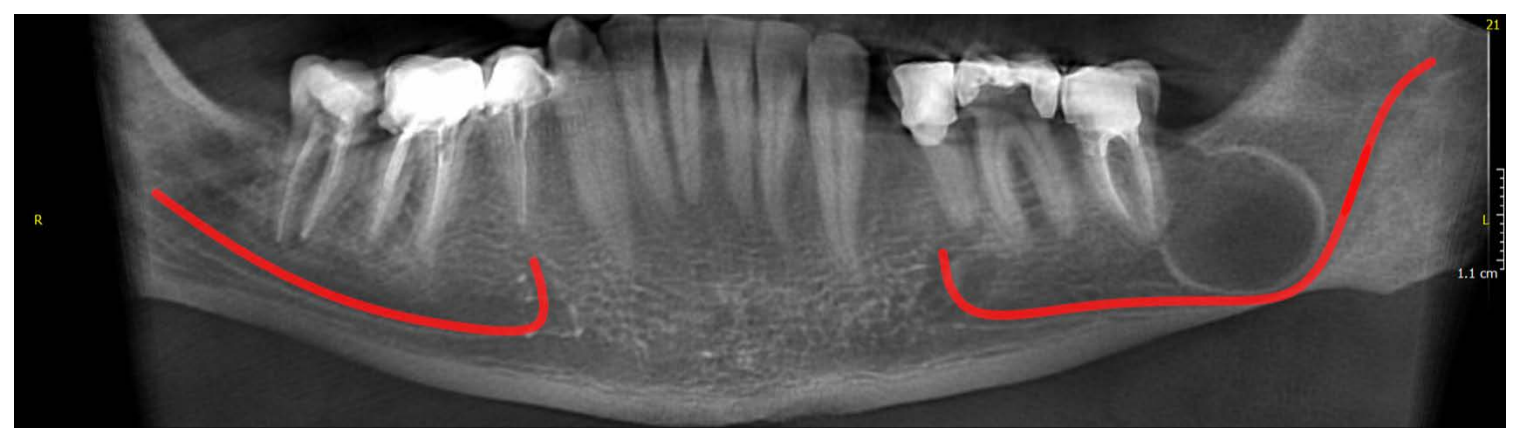

Fig. 4. A panoramic reconstructed cone-beam computed tomographic image shows downward displacement of the mandibular canal in a patient with an aneurysmal bone cyst.

\section{Odontogenic keratocyst}

Odontogenic keratocysts are a relatively common type of developmental odontogenic cysts, accounting for $10 \%$ to $12 \%$ of all jaw cysts. They have a slight male predilection. ${ }^{12}$ The mean age of patients affected by odontogenic keratocysts was reported to be 42 years, and this lesion has a peak incidence in the second to fifth decades of life. ${ }^{10}$ More than $80 \%$ of odontogenic keratocysts have been reported to occur in the mandible, with the highest frequency in the body of the mandible (20\%) followed by the angle of the mandible (18\%) and vertical ramus $(10 \%) .{ }^{10}$ Odontogenic keratocysts are often associated with pain, swelling, and drainage, and cause bone expansion and perforation in about $50 \%$ of patients. ${ }^{12}$ Radiographically, an odontogenic keratocyst manifests as a well-defined unilocular or multilocular radiolucent lesion, with smooth or scalloped and often corticated margins (Fig. 3). ${ }^{10,12}$ Odontogenic keratocysts grow in the anterior-posterior direction in the jawbone and do not cause considerable expansion. ${ }^{10}$ According to Abdi et al., ${ }^{4} 53.8 \%$ of odontogenic keratocysts caused buccal displacement, while $46.2 \%$ caused lingual displacement of the IANC. Moreover, Farman et al. ${ }^{9}$ found that odontogenic keratocysts may cause slight downward displacement of the IANC. However, it should be noted that this type of cyst can surround the mandibular canal. Large odontogenic keratocysts do not cause IANC displacement as other types of odontogenic cysts do.

\section{Aneurysmal bone cyst}

Aneurysmal bone cysts are osteolytic cystic lesions filled with blood, mainly involving the long bones. They are not common in the craniofacial region, and only $2 \%$ of cases occur in the jaws. The mandible is more commonly affected than the maxilla. The body of the mandible (90\%) and mandibular ramus (30\%) are the most commonly affected regions. However, their occurrence in the coronoid process and the mandibular condyle is rare $(2 \%) .{ }^{13}$ This type of cyst has a predilection for females and usually occurs in the first 3 decades of life. ${ }^{14}$ An aneurysmal bone cyst is a painful and rapidly growing cyst that causes bone swelling. Areas involved with an aneurysmal bone cyst may be tender on palpation. ${ }^{15}$ Their radiographic appearance (Fig. 4) may vary from unilocular radiolucency to a "ballooned-out" multilocular radiolucency with a honeycomb or soap-bubble pattern. ${ }^{14,15}$ Aneurysmal bone cysts can cause expansion, destruction and perforation of bone, and 


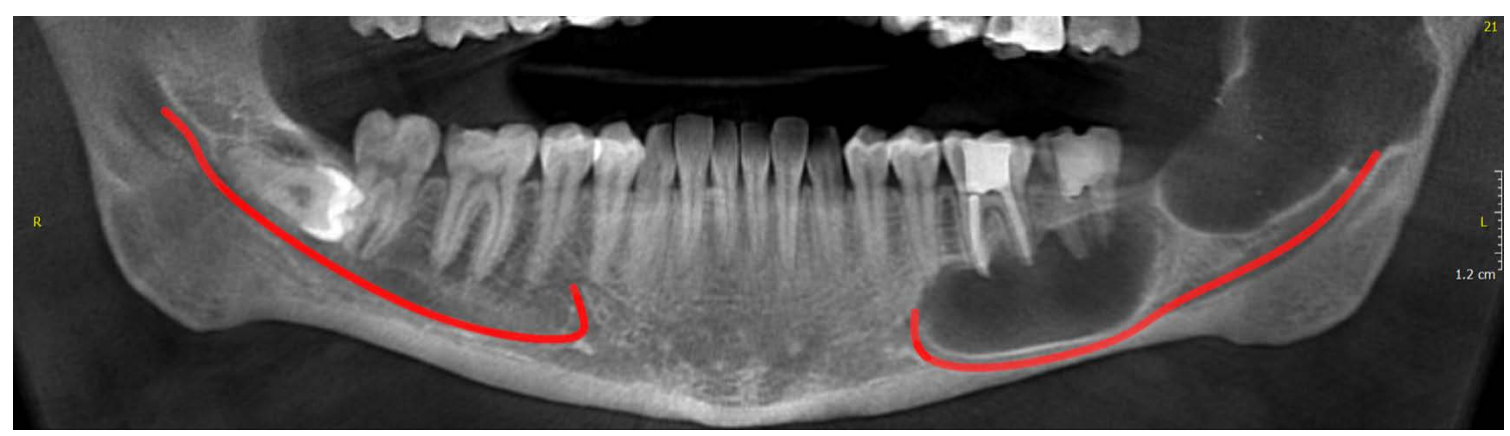

Fig. 5. A panoramic reconstructed cone-beam computed tomographic image shows the inferiorly displaced mandibular canal in a patient with ameloblastoma.

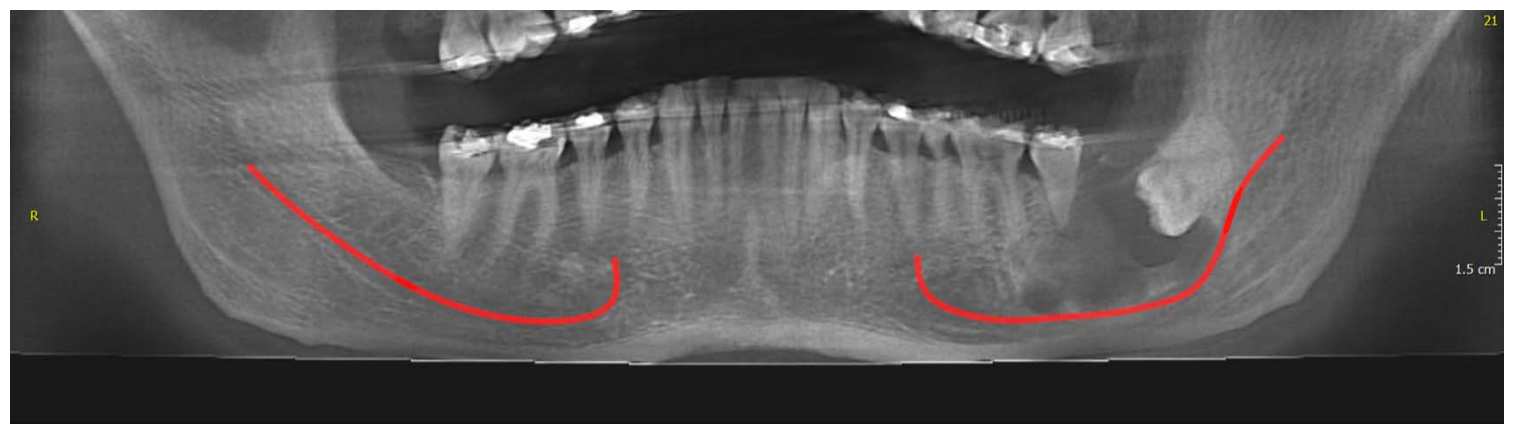

Fig. 6. A panoramic reconstructed cone-beam computed tomographic image shows inferior displacement of the mandibular canal in a patient with central giant cell granuloma.

soft tissue herniation. ${ }^{15,16}$ Farman et al., ${ }^{9}$ Simsek et al., ${ }^{13}$ Pai et al., ${ }^{14}$ and Flores et al. ${ }^{16}$ reported inferior displacement of the IANC due to aneurysmal bone cysts. Sharma reported a case of inferior displacement of the left and right IANCs approximating the inferior border of the mandible caused by an aneurysmal bone cyst. ${ }^{15}$ However, according to Kolokytbas et al., ${ }^{17}$ vascular lesions such as aneurysmal bone cysts tend to displace the IANC towards the lingual cortex, while odontogenic neoplasms tend to displace the mandibular canal buccally.

\section{Ameloblastoma}

Ameloblastoma is the most common odontogenic neoplasm with an epithelial origin. It is usually found in the jawbone, and accounts for $11 \%$ to $13 \%$ of all odontogenic tumors. ${ }^{10,17}$ It has a slight predilection for males, and patients are often in the age range of 10-90 years, with a peak incidence in the third to fifth decades of life. ${ }^{10}$ Ameloblastoma often remains asymptomatic until reaches a large size, and it is more commonly seen in the mandible..$^{10,18}$ Radiographically (Fig. 5), it manifests as a multilocular (69\%) or unilocular cyst-like lesion. Its radiographic appearance varies from completely radiolucent to mixed with coarse and curved bony septae. These septae create a soap-bubble or honeycomb pattern. ${ }^{10}$ Ameloblastoma can cause displacement of the adjacent teeth, root resorption, and/or extensive bone expansion. ${ }^{19}$ According to Abdi, $84.6 \%$ of ameloblastomas cause buccal displacement of the IANC, and $15.4 \%$ cause lingual displacement. ${ }^{4}$ According to Kolokythas et al., ${ }^{17}$ buccal displacement of the IANC caused by odontogenic tumors may be explained based on the relationship of the developing tooth bud with the IANC and its contents. The tooth buds of permanent teeth are located lingual to their preceding deciduous teeth and the IANC. Therefore, tumors developing at tooth locations are positioned lingual to the IANC and as a result, displace the mandibular canal towards the mandibular buccal cortical plate. In contrast, Farman et al. ${ }^{9}$ demonstrated that the IANC is displaced downward in patients with ameloblastoma, similar to the pattern observed in patients with radicular and dentigerous cysts.

\section{Central giant cell granuloma}

Central giant cell granuloma is a benign proliferative intrabony lesion with an unclear etiology. Hemorrhage, inflammation, and trauma have been suggested as possible 
causes of central giant cell granuloma. It accounts for $<7 \%$ of benign lesions of the jaws. ${ }^{20}$ It has a predilection for females, and $60 \%$ of central giant cell granulomas are detected in individuals younger than 30 years of age. ${ }^{21}$ It is more commonly found in the anterior region of the jaws than in the posterior region. It often crosses the midline $50 \%$ of cases) and is more commonly seen in the mandible. ${ }^{20,21} \mathrm{Ra}-$ diographically (Fig. 6), it manifests as a unilocular to multilocular radiolucent lesion with well-defined margins. It often shows a stubble granular pattern of calcification, which may be organized into wispy septae. In some cases, the septae are located perpendicular to the periphery, dividing the internal space into several compartments and creating a honeycomb pattern. ${ }^{20}$ Central giant cell granuloma can cause displacement of the adjacent teeth and tooth buds, as well as root resorption. The lamina dura of the teeth within the lesion is usually missing. ${ }^{14,20}$ Pay et al. ${ }^{14}$ Chawla et al., ${ }^{20}$ Kamble et al., ${ }^{21}$ Gupta et al., ${ }^{22}$ and Baskaran et al. ${ }^{23}$ reported inferior displacement of the IANC due to central giant cell granuloma. Central giant cell granuloma, similar to aneurysmal bone cysts, can displace the IANC towards the mandibular lingual cortical plate. ${ }^{17}$ The reason for lingual displacement of the mandibular canal by anomalies with vascular origin such as aneurysmal bone cyst and central giant cell granuloma is not clearly understood. ${ }^{17} \mathrm{Ac}-$ cording to Kolokytbas et al., ${ }^{17}$ vascular components of the neurovascular bundle are often located buccal to the IANC, and vascular lesions therefore cause lingual displacement of the mandibular canal.

\section{Fibrous dysplasia}

Fibrous dysplasia is a hamartomatous, benign, fibro-osseous, developmental disorder of the bone. It has a predilection for long bones (such as the femur), ribs, and craniofacial bones. It often develops as the result of a mutation in the gene encoding the alpha-subunit of stimulatory $\mathrm{G}$ protein. ${ }^{24,25}$ Fibrous dysplasia has 2 primary categories: (1) monostotic fibrous dysplasia, characterized by the involvement of only 1 bone; and (2) polyostotic fibrous dysplasia, characterized by the involvement of several bones. Monostotic fibrous dysplasia is often diagnosed in the first to third decades of life, with no sex or race predilection. Up to $85 \%$ of patients with fibrous dysplasia suffer from the monostotic type. ${ }^{24}$ The second age peak for fibrous dysplasia is the fourth to sixth decades of life. Polyostotic fibrous dysplasia is less frequent, and is associated with skin pigmentation and endocrine disturbances in about 3\% of patients. It is more common in young females. ${ }^{24}$ Among facial bones, the mandible is most commonly affected by fibrous dysplasia. ${ }^{25}$ On radiography, ill-defined, mixed to radiopaque areas with ground-glass or orange-peel patterns are seen ${ }^{24,25}$ According to MacDonald Jankowski and $\mathrm{Li}^{26}$ fibrous dysplasia may cause swelling of the buccolingual and inferior mandibular cortical bone in around $80 \%$ of patients. Displacement of the IANC occurs in over $60 \%$ of patients. Maxillary sinus involvement is detected in almost all cases of fibrous dysplasia affecting the maxilla. Tooth/ root displacement is found in up to $50 \%$ of patients, and root resorption occurs in fewer than $5 \%$ of patients. In a study by de Noronha Santos Netto et al., ${ }^{24} 20 \%$ and $64 \%$ of patients with fibrous dysplasia suffered from displacement of the IANC and maxillary sinus floor, respectively. Upward displacement of the mandibular canal has been considered pathognomonic for fibrous dysplasia by some authors. ${ }^{27,28}$ Harmon et al., ${ }^{29}$ Giunta et al., ${ }^{30}$ and Goldberg and Sperling $^{31}$ reported similar results regarding displacement of the IANC in patients with fibrous dysplasia. In addition to superior displacement of the mandibular canal, Nityasri et al. ${ }^{25}$ showed its inferior displacement due to fibrous dysplasia in a radiographic retrospective study.

\section{Cemento-ossifying fibroma}

Cemento-ossifying fibroma is a benign fibro-osseous lesion with neoplastic behavior. ${ }^{24}$ The pathogenesis of cemento-ossifying fibroma has yet to be clearly established; however, congenital anomalies and trauma in the process of maturation of dental structures may be responsible for the occurrence of cemento-ossifying fibroma. ${ }^{32}$ Women in their second to fourth decades of life are commonly affected. Cemento-ossifying fibroma most commonly involves the mandible (93\%), particularly the molar area $(61 \%)$, followed by the premolar (28\%) and canine-incisor $(11 \%)$ regions. ${ }^{24,32}$ Cemento-ossifying fibroma often manifests as a painless and round mass that grows and expands slowly. ${ }^{32}$ Radiographically, cemento-ossifying fibroma is radiolucent in its early stages of development. As the lesion matures, it becomes mixed radiolucent and radiopaque, and eventually completely radiopaque. ${ }^{32}$ In 3 different studies, MacDonald-Jankowski ${ }^{33-35}$ revealed that cemento-ossifying fibroma may cause IANC displacement in over $50 \%$ of patients. As described in those studies, over $80 \%$ of cases of cemento-ossifying fibroma of the maxilla cause maxillary sinus involvement. Tooth/root displacement occurs fairly frequently, in $<25 \%$ of cases, and root resorption occurs in around $20 \%$ of patients with cemento-ossifying fibroma. De Noronha Santos Netto et al. ${ }^{24}$ reported that displacement of the IANC, maxillary sinus floor, and adjacent teeth/roots occurred in $56 \%, 67 \%$, and $60 \%$ of cemento-os- 
sifying fibroma patients, respectively. In contrast, Farman et al. showed displacement of the mandibular canal without erosion of its cortical plate by cemento-ossifying fibroma. ${ }^{9}$ Fanibunda and Reed ${ }^{36}$ and Saikrishna et al. ${ }^{37}$ showed downward displacement of the mandibular canal in patients with cemento-ossifying fibroma.

\section{Discussion}

As presented in Table 1, which contains a summary of the results, jaw lesions causing IANC displacement can be generally divided into 5 categories: odontogenic cysts (including radicular cysts, dentigerous cysts, and odontogenic keratocysts), pseudocysts (aneurysmal bone cysts), odontogenic tumors (ameloblastoma), reactive lesions (central giant cell granuloma), and fibro-osseous lesions (fibrous dysplasia and cemento-ossifying fibroma). Of those types of lesions, fibrous dysplasia causes superior displacement of the IANC, while the other lesions all cause inferior displacement of the IANC. This finding is so important that superior displacement of the mandibular canal is considered pathognomonic for the diagnosis of fibrous dysplasia. ${ }^{27,28}$ The lesions involving the IANC do not show significant differences in terms of the age and sex of affected patients. Ameloblastoma and fibrous dysplasia cause the greatest displacement of the IANC, although mandibular canal displacement by these lesions is in completely opposite directions. Radiographically, all of these lesions are well-defined, except for fibrous dysplasia, and almost all have a significantly higher prevalence in the mandible.

Among cystic lesions, radicular cysts are related to necrotic teeth, ${ }^{5}$ while the other lesions are related to vital or impacted teeth. ${ }^{10}$ Moreover, all these lesions are located peri-apically except for dentigerous cysts, which have a peri-coronal position. ${ }^{10-13}$ The high extension and low expansion of odontogenic keratocysts and the ballooning expansion of aneurysmal bone cysts can be of great value for diagnosing them correctly. ${ }^{10,14,15}$

It should be noted that although aneurysmal bone cysts occur in younger patients than the other cystic lesions discussed above, its frequency in the jawbone is much lower than that of the other lesions. ${ }^{13}$ Moreover, all these cystic lesions cause inferior displacement of the IANC; the displacement caused by odontogenic keratocysts has a buccal inclination, while the displacement caused by aneurysmal bone cysts has a lingual inclination. Among odontogenic tumors, ameloblastoma is the most common and causes the greatest displacement of the IANC. The strong tendency of ameloblastoma to cause inferior and buccal displacement of the IANC should be considered in surgical procedures in this region to minimize traumatization of the mandibular canal. ${ }^{17}$

Central giant cell granuloma is a reactive lesion of the jaw that causes IANC displacement similar to that caused by aneurysmal bone cysts. Regarding the fibro-osseous lesions, it should be noted that fibrous dysplasia is originally a hamartoma, and therefore has a long history. In other words, it is a developmental defect, whereas cemento-ossifying fibroma is a true neoplasm and may have a shorter history. Furthermore, fibrous dysplasia has ill-defined margins, whereas cemento-ossifying fibroma has well-defined borders and is surrounded by a radiolucent rim, which aids in its diagnosis. Furthermore, as stated earlier, the direction of mandibular canal displacement by cemento-ossifying fibroma and fibrous dysplasia is opposite. ${ }^{24,25,32,34}$

Considering all the above, the 8 types of lesions discussed herein should be suspected in cases of IANC displacement, and the differential diagnosis should take into account the characteristics of this displacement. Additionally, following the diagnosis of one of these lesions, IANC displacement should be expected as the lesion matures. These findings can help surgeons perform more efficient and safer surgical procedures and highlight the significance of radiography in diagnosis and treatment planning.

\section{References}

1. Srinivasan K, Seith A, Gadodia A, Sharma R, Kumar A, Roychoudhury A, et al. Evaluation of the inferior alveolar canal for cysts and tumors of the mandible-comparison of multidetector computed tomography and 3-dimensional volume interpolated breath-hold examination magnetic resonance sequence with curved multiplanar reformatted reconstructions. J Oral Maxillofac Surg 2012; 70: 2327-32.

2. de Oliveira-Santos C, Souza PH, de Azambuja Berti-Couto S, Stinkens L, Moyaert K, Rubira-Bullen IR, et al. Assessment of variations of the mandibular canal through cone beam computed tomography. Clin Oral Investig 2012; 16: 387-93.

3. Boeddinghaus R, Whyte A. Current concepts in maxillofacial imaging. Eur J Radiol 2008; 66: 396-418.

4. Abdi I, Taheri Talesh K, Yazdani J, Keshavarz Meshkin Fam S, Ghavimi MA, Arta SA. The effect of ameloblastoma and keratocystic odontogenic tumor on the displacement pattern of inferior alveolar canal in CBCT examinations. J Dent Res Dent Clin Dent Prospects 2016; 10: 155-61.

5. Mortazavi H, Baharvand M. Review of common conditions associated with periodontal ligament widening. Imaging Sci Dent 2016; 46: 229-37.

6. Jamdade A, Nair GR, Kapoor M, Sharma N, Kundendu A. Localization of a peripheral residual cyst: diagnostic role of CT scan. Case Rep Dent 2012; 2012: 760571.

7. Karam N, Karam F, Nasseh I, Noujeim M. Residual cyst with a 
misleading clinical and radiological appearance. J Oral Maxillofac Radiol 2013; 1: 17-20.

8. Shivhare P, Singh A, Haidry N, Yadav M, Shankarnarayan L. Multilocular radicular cyst - a common pathology with uncommon radiological appearance. J Clin Diagn Res 2016; 10: ZD13-5.

9. Farman AG, Nortjé CJ, Grotepass FW. Pathological conditions of the mandible: their effect on the radiographic appearance of the inferior dental (mandibular) canal. Br J Oral Surg 1977; 15 : 64-74.

10. Mortazavi H, Baharvand M. Jaw lesions associated with impacted tooth: a radiographic diagnostic guide. Imaging Sci Dent 2016; 46: 147-57.

11. Zerrin E, Husniye DK, Peruze C. Dentigerous cysts of the jaws: clinical and radiological findings of 18 cases. J Oral Maxillofac Radiol 2014; 2: 77-81.

12. Yonetsu K, Bianchi JG, Troulis MJ, Curtin HD. Unusual CT appearance in an odontogenic keratocyst of the mandible: case report. AJNR Am J Neuroradiol 2001; 22: 1887-9.

13. Simsek HO, Yildirim D, Gormez O, Yuce E, Kapucuoglu FN. Aneurysmal bone cyst of the mandible: report of a case with a review of the literature. J Oral Maxillofac Radiol 2014; 2: 647.

14. Pai D, Kamath AT, Kudva A, Solomon MM, Kumar S, Sasikumar P. Concomitant central giant cell granuloma and aneurysmal bone cyst in a young child. Case Rep Dent 2017; 2017: 6545848.

15. Sharma GH, Dabir AV, Das DA, Talreja-Kanchan PP. Bilateral aneurysmal bone cyst of the mandible: a case report. J Indian Acad Oral Med Radiol 2015; 27: 479-83.

16. Flores IL, Hamilton ME, Zanchin-Baldissera E, Uchoa-Vasconcelos AC, Chaves-Tarquinio SB, Neutzling-Gomes AP. Simple and aneurysmal bone cyst: aspects of jaw pseudocysts based on an experience of Brazilian pathology service during 53 years. Med Oral Patol Oral Cir Bucal 2017; 22: e64-9.

17. Kolokythas A, Al-Ghamian H, Miloro M. Does a difference exist in inferior alveolar canal displacement caused by commonly encountered pathologic entities? An observational study. J Oral Maxillofac Surg 2011; 69: 1944-51.

18. Gümgüm S, Hoşgören B. Clinical and radiographic behaviour of ameloblastoma in 4 cases. J Can Dent Assoc 2005; 71: 4814.

19. Avril L, Lombardi T, Ailianou A, Burkhardt K, Varoquaux A, Scolozzi P, et al. Radiolucent lesions of the mandible: a pattern-based approach to diagnosis. Insights Imaging 2014; 5: 85101.

20. Chawla C, Rao PK, Kini R, Bhandarkar GP, Kashyap R, Holla V. Central giant cell granuloma - a case report. Am J Diagn Imaging 2017; 2: 17-20.

21. Kamble KA, Guddad SS, Guddad SS, Lingappa A. Central giant cell granuloma: a case report with review of literature. $\mathrm{J}$
Indian Acad Oral Med Radiol 2016; 28: 98-101.

22. Gupta M, Gupta M, Singh S, Kaur R. Central giant cell granuloma of the maxilla. BMJ Case Rep 2013; 2013. pii: bcr2013 009102.

23. Baskaran P, Gopal M, Rastogi V, Misra SR. Aggressive central giant cell granuloma of the mandible, a diagnostic dilemma. $\mathrm{J}$ Oral Maxillofac Radiol 2015; 3: 88-91.

24. de Noronha Santos Netto J, Machado Cerri J, Miranda AM, Pires FR. Benign fibro-osseous lesions: clinicopathologic features from 143 cases diagnosed in an oral diagnosis setting. Oral Surg Oral Med Oral Pathol Oral Radiol 2013; 115: e5665.

25. Nityasri V, Haris PS, Bose T, Balan A. Fibrous dysplasia - a 13-year retrospective radiographic analysis in a south Indian population. Dentomaxillofac Radiol 2011; 40: 282-9.

26. Macdonald-Jankowski DS, Li TK. Fibrous dysplasia in a Hong Kong community: the clinical and radiological features and outcomes of treatment. Dentomaxillofac Radiol 2009; 38: 6372.

27. Petrikowski CG, Pharoah MJ, Lee L, Grace MG. Radiographic differentiation of osteogenic sarcoma, osteomyelitis and fibrous dysplasia of the jaws. Oral Surg Oral Med Oral Pathol Oral Radio Endod 1995; 80: 744-50.

28. Singer SR, Mupparapu M, Rinaggio J. Clinical and radiographic features of chronic monosotic fibrous dysplasia of the mandible. J Can Dent Assoc 2004; 70: 548-52.

29. Harmon M, Arrigan M, Toner M, O'Keeffe SA. A radiological approach to benign and malignant lesions of the mandible. Clin Radiol 2015; 70: 335-50.

30. Giunta JL, Heffez L, Doku HC. Superior and buccal displacement of the mandibular canal in fibrous dysplasia. J Oral Maxillofac Surg 1985; 43: 460-2.

31. Goldberg MH, Sperling A. Gross displacement of the mandibular canal: a radiographic sign of benign fibro-osseous bone disease. Oral Surg Oral Med Oral Pathol 1981; 51: 225-8.

32. Mortazavi H, Baharvand M, Rahmani S, Jafari S, Parvaei P. Radiolucent rim as a possible diagnostic aid for differentiating jaw lesions. Imaging Sci Dent 2015; 45: 253-61.

33. MacDonald-Jankowski DS. Cemento-ossifying fibromas in the jaws of Hong Kong Chinese. Dentomaxillofac Radiol 1998; 27 : 298-304.

34. MacDonald-Jankowski DS, Li TK. Ossifying fibroma in a Hong Kong community: the clinical and radiological features and outcomes of treatment. Dentomaxillofac Radiol 2009; 38: 514-23.

35. MacDonald-Jankowski DS. Ossifying fibroma: a systematic review. Dentomaxillofac Radiol 2009; 38: 495-513.

36. Fanibunda K, Reed MF. Cemento-ossifying fibroma of the mandible. Dentomaxillofac Radiol 1997; 26: 246-8.

37. Saikrishna D, Shetty S, Ramya S. Massive ossifying fibroma of mandible. Ann Maxillofac Surg 2014; 4: 81-4. 